Buana Sains Vol 17 No 1: 1 - 8, 2017

\title{
ORDINASI SUNGAI BIRU DESA TULUNGREJO KECAMATAN BUMIAJI KOTA BATU BERDASARKAN MAKROZOOBENTHOS
}

\author{
Lorine Tantalu $^{1}$, Sri Sudaryanti ${ }^{2}$ dan Mulyanto $^{2}$ \\ 1Program Studi Teknologi Industri Pertanian, Fakultas Pertanian Universitas Tribhuwana \\ Tunggadewi \\ 2Program Studi Manajemen Sumberdaya Perairan, Fakultas Perikanan dan Ilmu Kalutan \\ Universitas Brawijaya
}

\begin{abstract}
This research aim to make ordination of Blue Rivers on Dusun Wonorejo, Desa Tulungrejo, Kecamatan Bumiaji, Kota Batu based on macrozoobenthos and environmental variable which support. The research is conducted in the early of February to mid of August. Items at the research consisting of macrozoobenthos community, water, environmental physical on Blur Rivers. Intake of some sample conducted in 15 sites which done only one intake as long as Blue River which representing reference site area. Way of intake of the makrozoobenthos sample are done with kicking sampling methods. Macrozoobenthos which had been taken would be identified and calculated as data sampling. Data analysis technique use CANOCO ("Canonical Community Ordination") programs on 4.5 version for determining the ordination of ecology group based on makrozoobenthos. From data analysis use CANOCO to be got Blue River ordination from 15 sites that is A ordination counted 7 site that means are good condition proven by finding of Glossomatidae. B ordination counted 8 site that means are site that begin to degradation proven by finding of Simuliidae.
\end{abstract}

Keywords: Ordination, Blue River, Makrozoobenthos

\section{Pendahuluan}

Sungai Biru merupakan salah satu anak sungai yang masuk ke dalam Sungai Brantas. Lingkungan di sekitar Sungai Biru merupakan daerah hutan primer yang saat ini mulai terancam keberadaannya karena adanya aktvitas manusia yang mengeksploitasi sumberdaya alam secara besar - besaran, akibatnya debit air sumber menjadi berkurang. Penelaahan sungai biru sebagai kawasan konservasi perlu dilakukan mengingat keberadaan "reference site" di kawasan DAS Brantas mulai berkurang. Data Inventarisasi Mata Air Wilayah Dinas Sumberdaya Air dan Energi Kota Batu (ESP, 2005), mata air
Sumber biru yang terletak di Dusun Wonorejo, Desa Tulungrejo Kecamatan Bumiaji tersebut masih dalam status kepemilikan Perhutani. Debit maksimal Sumber Biru mencapai $25 \mathrm{l} / \mathrm{dt}$ dan debit minimalnya pada kisaran $17 \mathrm{l} / \mathrm{dt}$, dan sampai data ini disusun Sumber Biru masih belum digunakan untuk air minum penduduk setempat atau untuk air baku sawah. Air yang berasal dari Sumber Biru ini akan bertemu dengan sumber air yang lain yang terletak pada lereng Gunung Biru dan membentuk aliran Sungai Biru. Salah satu langkah yang dapat untuk mengevaluasi kualitas air Sungai Biru adalah dengan pengujian menggunakan makrozoobenthos. Menurut Sudaryanti 
L. Tantalu, S. Sudaryanti dan Mulyanto / Buana Sains Vol 17 No 1 : 1-8

(1997) makrozoobenthos adalah organisme yang hidup di dasar substrat (sedimen, debris, batang kayu, macrophyta dan alga filamen) di habitat perairan, pada sebagian siklus hidupnya dan tertahan pada ukuran mata jaring 200 sampai $500 \mu \mathrm{m}$. Menurut Sudaryanti (1997) makrozoobenthos memiliki keuntungan sebagai biomonitor yaitu (1) sebagian besar hidup menetap (2) efek polusi lokal dapat terdeteksi (3) kunci identifikasi tersedia untuk beberapa kelompok (4) peralatan sederhana (5) beberapa spesies mempunyai toleransi lebar dan beberapa spesies mempunyai toleransi sempit. Tujuan dari penelitian ini adalah untuk mengetahui komunitas makrozoobenthos dan membuat ordinasi Sungai Biru berdasarkan komunitas makrozoobenthos.

\section{Materi dan Metode}

\section{Materi Penelitian}

Lokasi penelitian berada di Sungai Biru Dusun Wonorejo, Desa Tulungrejo, Kecamatan Bumiaji, Kota Batu, Jawa Timur, identifikasi dilakukan di Laboratorium Ilmu - Ilmu Perairan (IIP) Fakultas Perikanan Universitas Brawijaya Malang. Materi pada penelitian ini adalah makrozoobenthos, kondisi fisik lingkungan pengambilan sampel (naungan, pasang surut (pasut), lumut, arus, makrofita dan kemiringan), dan substrat dasar perairan sungai (deposit sediment (CPOM), plume (lumut halus pada substrat), dan lokal NPS).

\section{Metode Penelitian}

Metode yang digunakan dalam penelitian ini adalah metode survei. Survei pada umumnya melakukan pengumpulan data sejumlah unit (satuan) individu dalam waktu yang bersamaan (Marzuki,1983). Metode survei bertujuan untuk membedah dan menguliti serta mengenal masalah - masalah sehingga mampu mendapatkan pembenaran terhadap keadaan dan praktik - praktik yang sedang berlangsung (Nazir, 2003)

Penentuan Stasiun Pengambilan Sampel

Sungai Biru merupakan daerah yang masih alami, dimana melewati daerah di Dusun Wonorejo Desa Tulungrejo Kecamatan Bumiaji Kota Batu dengan jarak $9 \mathrm{~km}$ dari Sumber Biru I sampai sebelum pertemuan dengan aliran dari Desa Sumber Brantas. Pengambilan sampel makrozoobenthos terdapat pada 15 stasiun "reference site" dimana pada masing - masing stasiun terdapat mata air. Jarak antar masing - masing stasiun diantaranya (1) stasiun I sampai VII berkisar antara $200-300 \mathrm{~m}$, (2) stasiun VIII sampai XII berkisar antara 300 $400 \mathrm{~m}$, dan (3) stasiun XIII sampai XV berkisar antara $50-200 \mathrm{~m}$.

\section{Metode Pengambilan Sampel}

\section{Makrozoobenthos}

Menurut Sudaryanti (2004) penggunaan jala tangan untuk pengambilan sampel makroinvertebrata umumnya digunakan pada perairan yang dangkal (dimana untuk Jawa Timur memiliki kedalaman sungai kurang dari $1 \mathrm{~m})$ sehingga memungkinkan peneliti untuk melakukan secara langsung pengambilan sampel di sungai sepanjang total $10 \mathrm{~m}$ di daerah "riffle". Penggunaan metode dengan jala tangan ini ditujukan untuk analisis sampel secara kualitatif, sehingga tidak diperlukan satuan unit pengambilan sampel. Hasilnya akan memberikan keluaran komposisi taxa yang dapat mencerminkan kondisi lokal kualitas perairan sungai. Jala tangan yang digunakan untuk pengambilan sampel terdiri atas pegangan dan sebuah jala yang telah diberi kerangka dimana tempat organisme dikumpulkan. Jala tangan ini memiliki lebar 200 sampai 400 $\mathrm{mm}$, tinggi $2-3 \mathrm{~m}$, bahu (penguat) 100 $-200 \mathrm{~mm}$ dan ukuran mata jala $500 \mu \mathrm{m}$. 
Prosedur pengambilan sampel menurut Sudaryanti (2004) adalah sebagai berikut: 1. Tiang jala dipegang dengan arah melawan arus; 2. Dasar perairan diaduk dengan 2 kaki secara bersama - sama untuk melepaskan organisme dari dasar perairan. Organisme akan masuk ke dalam jala; 3. Bagian dalam jala diperiksa kalau ada batu atau ranting. Batu atau ranting tersebut dicuci di dalam jala; 4. Pengambilan sampel diulangi di daerah "riffle" sampai total sepanjang $10 \mathrm{~m} ; 5$. Organsime dicuci dengan air dan dikumpulkan pada salah satu sudut jala dengan terus menyiram air, hal ini untuk kemudahan pengambilan sampel dari dalam jala; 6. Jala dibalik ke arah luar untuk memindahkan sampel ke dalam wadah sampel; 7. Pengawetan sampel dilakukan dengan alkohol 96\%.

\section{Metode Pengukuran Faktor Ekologis}

Pengukuran nir kualitas air meliputi kecepatan arus diukur dengan menggunakan metode Panduan Praktikum Limnologi (2004) dan substrat dasar dengan menggunakan merode Sudaryanti (1997). Pengamatan kondisi fisik lingkungan yang diamati adalah deposit sedimen (CPOM), naungan, makrofita, plume (bulu halus pada substrat), kemiringan, perifito (tanaman yang menempel pada lereng sungai), lumut, lokal NPS (kemungkinan masuknya nitrogen dari pestisida pertanian) dan detrititus pada substrat.Kualitas air oksigen terlarut menggunakan metode Panduan Praktikum Limnologi (2004).

\section{Analisis Data}

Makrozoobenthos diidentifikasi sampai degan tingkat famili kecuali untuk Oligochaeta ("class"), Acarina ("ordo"), dan Chironomide ("sub famili") (Sudaryanti, et al., 2001). Kemudian dilanjutkan dengan analisis data menggunakan program CANOCO ("Canonical Community Ordination").
Program CANOCO dirancang untuk analisis dalam studi ekologi komunitas. Distribusi faktor lingkungan diplotkan dalam suatu diagram ordinasi, yang menggambarkan habitat yang disukai oleh taxa. Penelitian benthos dengan menggunakan program CANOCO sudah dilakukan untuk klasifikasi dan ordinasi Sungai Brantas (Sudaryanti, 1995). Pembacaan ordinasi pada penelitian ini yaitu melalui "profesional judgment" dan melalui hasil penelitian sebelumnya yaitu penelitian Sudaryanti (1998) yang menggunakan program CANOCO.

\section{Hasil dan Pembahasan}

\section{Deskripsi Daerah Penelitian}

Dusun Wonorejo tersebut merupakan daerah dataran tinggi $(1400-1600 \mathrm{dpa})$, dan memiliki potensi pariwisata yang berupa Coban Talun. (Dusun Wonorejo, 2007). Salah satu sungai yang berasal dari Dusun Wonorejo dan juga merupakan anak sungai yang masuk ke dalam Sungai Brantas, adalah Sungai Biru yang berasal dari mata air Sumber Biru yang terletak di Gunung Biru. Sumber Biru itu sendiri memiliki debit air maksimal sebanyak 25 1/dt dan debit air minimal sebanyak 17 $1 / \mathrm{dt}$, perlu diketahui pula bahwa sumber mata air tersbut masih belum dipergunakan untuk aktivitas penduduk di Dusun Wonorejo (ESP, 2005). Deskripsi stasiun selengkapnya tercantum dalam Tabel 1.

\section{Ordinasi Sungai Biru Berdasarkan Makrozoobenthos}

Hasil analisis data dengan menggunakan CANOCO didapatkan ordinasi Sungai Biru yang disesuaikan dengan kualitas air dan faktor fisik lingkungannya. Lampiran 7 dan Lampiran 8 menunjukkan diagram ordinasi Sungai Biru berdasarkan makrozoobenthos yang didukung oleh kualitas air dan fisik lingkungan. Dari diagram tersebut didapatkan bahwa 
ordinasi tersebut terbagi menjadi dua bagian yaitu ordinasi A untuk bagian kiri yang tergolong merupakan daerah stasiun

yang baik dan ordinasi B untuk bagian kanan yang tergolong daerah stasiun yang kurang baik.

Tabel 1. Deskripsi Stasiun

\begin{tabular}{|c|c|c|c|c|}
\hline Stasiun & Kondisi Sekitar & Lebar Sungai (m) & Tipe Aliran & Substrat \\
\hline 1 & Hutan Primer & 2.55 & Riffle & Cobble dan pebble \\
\hline 2 & Hutan Primer & 2.3 & Riffle & Cobble \\
\hline 3 & Hutan Primer & 0.76 & Riffle & Sand dan Cobble \\
\hline 4 & Hutan Primer & 2.15 & Riffle & Boulder dan Cobble \\
\hline 5 & Hutan Primer & 2.15 & Riffle & Boulder dan Cobble \\
\hline 6 & Hutan Primer & 1.45 & Riffle & Sand dan Gravel \\
\hline 7 & Hutan Primer & 2.65 & Riffle & Cobble dan Pebble \\
\hline 8 & Hutan Primer & 3.25 & Riffle & Cobble dan Pebble \\
\hline 9 & Hutan Primer & 3.05 & Riffle & $\begin{array}{l}\text { Pebble, Cobble, Gravel dan } \\
\text { Sand }\end{array}$ \\
\hline 10 & Hutan Primer & 3.05 & Riffle & Pebble dan Cobble \\
\hline 11 & Hutan Primer & 3.25 & Riffle & Bedrock dan Cobble \\
\hline 12 & Hutan Primer & 3.65 & Riffle & Pebble dan Cobble \\
\hline 13 & $\begin{array}{l}\text { Padang } \\
\text { Rumput }\end{array}$ & 8.24 & Riffle & Pebble dan Cobble \\
\hline 14 & $\begin{array}{l}\text { Padang } \\
\text { Rumput }\end{array}$ & 0.55 & Riffle & Sand dan Gravel \\
\hline 15 & $\begin{array}{l}\text { Padang } \\
\text { Rumput }\end{array}$ & 2.5 & Riffle & Sand dan Silt \\
\hline
\end{tabular}

Keterangan : Silt (0.004-0.06 mm), Sand (0.06-2 mm), Gravel $(2-16 \mathrm{~mm})$, Pebble (16-64 mm), Cobble (64-256 mm), Boulder (> $256 \mathrm{~mm})$, Bedrock (Batu padas).

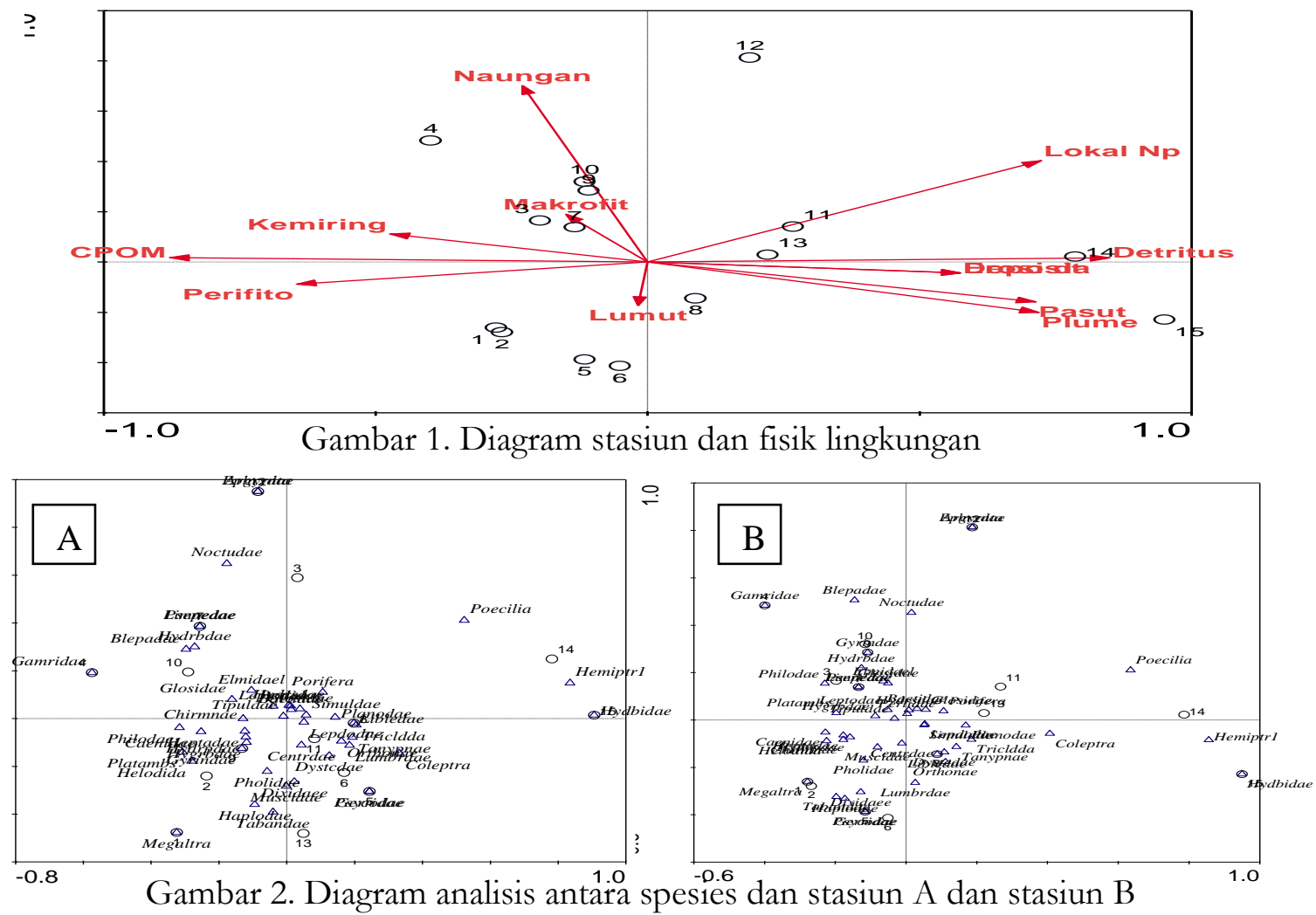


Hasil analisis data menggunakan program CANOCO memetakan dua wilayah ordinasi yaitu ordinasi A dan ordinasi B. Gambar 2. diketahui spesies yang terdapat pada ordinasi A (ordinasi diagram bagian kiri) meliputi statisun 1 , 2, 4, 7, 9, 10, dan 12, dengan famili Ephrydidae (1 ekor), Argyronela (1 ekor), Limnephilidae (3 ekor), Psephenidae (1 ekor), Hydropbilidae (15 ekor), Bleparoceritidae (5 ekor), Elmidae larva (40 larva), Glosossomatidae (31 ekor), Leptoceridae (496 ekor), Perlidae (134 ekor), Tipulidae (20 ekor), Chironominae (25 ekor), Baetidae (1317 ekor), Philopotamidae (12 ekor), Caenidae (13 ekor), Heptagenidae (216 ekor), Gyrinida (1 ekor), Hygrobiidae (16 ekor), Dysticidae Platambus (1 ekor), Pholicentropodidae (16 ekor), Dixidae (3 ekor), Muscidae (4 ekor), Haplotaxidae (2 ekor), Tabanidae (1 ekor), Gammaridae (1 ekor) dan Megaloptera (1 ekor) dimana pada ordinasi A tersebut berada pada stasiun Pada ordinasi A, kecepatan arus dan naungan yang tinggi. Menurut Sudaryanti (2003a) Perlidae, Heptagenidae, Philopotamidae, Leptoceridae, Limnephilidae, dan larva Megaloptera mencerminkan kondisi perairan sungai masih sehat. Menurut Suwignyo et al., (2005) Dysticidae terutama hidup di perairan dengan substrat jernih yang banyak tumbuhan airnya. Psephenidae hidup dalam sungai yang dangkal dan berarus deras dengan substrat batu dan kerikil.

Tipulidae hidup di dasar sungai dan dekat mata air (Borror, et al., 1992), Tipulidae termasuk "shredders" yaitu memakan daun - daun yang jatuh (Merrit dan Cummins, 1979). Menurut Macdonald (1990) "riffle beetles" (Coleoptera) merupakan indikator periaran yang sehat, sedangkan larva "caddiesflies" (Trichoptera) merupakan indikator perairan yang cukup sehat atau sedang. Menurut Sudaryanti (1992) Coleoptera memiliki sifat "shredders" yang memakan CPOM. Menurut Merrit dan Cummins (1979) Hydrophilidae memiliki sifat hidup di daerah yang memiliki banyak vegetasi. Keberadaan Baetidae dan Caenidae mencerminkan kondisi perairan cukup terdegradasi pencemaran organik. Menurut Sudaryanti (2003b), sungai yang memiliki taxa Glossosomatidae dan Elmidae memiliki status perairan yang sehat. Haplotaxidae merupakan makrozoobenthos yang hidup di daerah "streams" dan "rivers". Larva Bleparoceritidae hidup pada perairan beraliran deras (Borror, et al., 1992). Ditinjau dari keberadaan spesies yang menunjukkan status perairan sungai sehat yang tersebut diatas, didukung oleh kecepatan arus yang tinggi $(37-78$ $\mathrm{cm} / \mathrm{dt}$ ) dengan kandungan oksigen terlarut yang tinggi pula $(6,9-9, \mathrm{mg} / \mathrm{l})$, ditunjang pula dengan naungan dan kandungan CPOM yang tinggi $(90 \%$ dan $100 \%$ ).

Berbeda halnya dengan ordinasi bagian kanan atau disebut dengan ordinasi B, spesies yang ditemukan meliputi famili Hydropsychidae, Simuliidae, Planorbidae, Libellulidae, Porifera, Ceratopogonidae, Tricladida, Lepidostomatidae, Lumbriculidae, Tanypodinae, Orthocladinae, Coleoptera sp., Psychomidae, Gerridae, Hemiptera sp., dan Hydrobiidae, dimana spesies tersebut terdapat pada stasiun 3, $5,6,8,9,13,14$, dan 15, dimana kondisi lingkungan dipengaruhi kondisi lingkungan yang didominasi oleh substrat plume yang terlihat dari substrat yang berlumut dan halus (cenderung tidak berbatu), dan detritus yang tinggi. Kecepatan arus dan CPOM pada ordinasi B berkisar antara (47, 48 dan 43 $\mathrm{cm} / \mathrm{dt}$ ), CPOM $70-80 \%$ dan rerata oksigen terlarut $7.5 \mathrm{mg} / \mathrm{ml}$. Baetidae dan Hydropsicychidae merupakan organisme "collectors". Menurut Wallace dan Webster dalam Sudaryanti et al., (2000b) "collectors" ("gatherers") atau 
L. Tantalu, S. Sudaryanti dan Mulyanto / Buana Sains Vol 17 No 1 : 1-8

pengumpul, merupakan hewan pemakan partikel bahan organik halus (diameter $<1 \mathrm{~mm}$ ). Menurut Sudaryanti (2003a) Hydropsychidae dan Simuliidae mencerminkan kondisi perairan yang cukup terganggu pencemaran organik. Simuliidae dapat ditemukan pada perairan yang berbatu, banyak mengandung sisa dekomposisi dan vegetasi, ditemukan mulai sungai bagian hulu sampai sungai yang besar ("streams" sampai "river"), begitu pula untuk Lumbriculidae. Hemiptera meliputi Gerridae hidup pada daerah "streams" dan "rivers" (Quigley, 1977), umumnya hidup pada perairan yang mneggenang (Borror et al., 1992). Larva Diptera seperti Ceratopogonidae yang hidup pada substrat berpasir sampai lumpur, sedangkan pada family Chironomidae utamanya pada subfamily Orthocladinae dan Tanypodinae biasa hidup di mana mana (Borror, 1992). Libellulidae atau nimfa capung tidak dapat hidup di perairan tercemar dengan kandungan oksigen yang rendah. Keberadaan Planorbidae dan Hydrobiidae menandakan bahwa perairaan tersebut beraliran lambat (Suwignyo, et al., 2005).

$$
\text { Pada diagram ordinasi }
$$

makrozoobenthos dapat dilihat bahwa keberadaan spesies dipengaruhi oleh fisik lingkungan dan kimianya. Hal ini terbukti bahwa untuk stasiun 3, 5 dan 6 yaitu pada diagram ordinasi berdasarkan kualitas air stasiun 3, 5, dan 6 yang berada di ordinasi B menjadi bagian dari ordinasi A pada diagram ordinasi berdasarkan fisik lingkungan. Hal ini diakibatkan karena stasiun yang memiliki kecepatan arus yang rendah (47, 48 dan $43 \mathrm{~cm} \mathrm{/dt)} \mathrm{tersebut} \mathrm{memiliki} \mathrm{nilai}$ CPOM yang cukup tinggi (100\%). Stasiun 12 juga mengalami hal yang sama, stasiun XII merupakan stasiun yang cenderung memiliki kandungan oksigen terlarut dan kecepatan arus yang tinggi
(7,5 $\mathrm{mg} / \mathrm{l})$, namun kawasan tersebut memiliki naungan yang tidak banyak (80 $\%$ dibandingkan dengan stasiun yang lain. Hal ini yang mengakibatkan stasiun 12 berada di ordinasi A menjadi ordinasi B. Perbedaan posisi stasiun 3, 5, 6 dari ordinasi $\mathrm{B}$ menjadi bagian dari ordinasi bagian kiri, dan begitu pula sebaliknya pada stasiun 12, menyebabkan adanya perbedaan keberadaan spesies. Ephrydidae, Argyronela, Baetidae, Dysticidae, dan Noctuidae pada diagram berdasarkan kualitas air berada pada ordinasi A, hal ini menandakan bahwa spesies tersebut cenderung menyukai daerah yang memiliki kandungan oksigen tinggi (6,5 9,4 mg/l) dan kecepetan arus yang cukup tinggi $(37-78 \mathrm{~cm} / \mathrm{dt})$, namun beralih menjadi bagian dari ordinasi bagian kanan pada diagram berdasarkan fisik lingkungan. Menurut Borror et al., (1992) organisme pengikal sarang laba - laba memiliki bentuk lingkungan yang khas sehingga membutuhkan daerah berarus lambat $(46 \mathrm{~cm} / \mathrm{dt})$. Baetidae tergolong makrozoobenthos yang hidup pada kondisi lingkungan apapun, terbukti bahwa Baetidae ditemukan disemua stasiun pengambilan sampel. Ceratopogonidae, Lumbriculidae, Psychomidae dan Gerridae yang merupakan bagian dari ordinasi bagian kanan pada diagram ordinasi berdasarkan kualitas air menjadi bagian dari ordinasi A pada diagram ordinasi berdasarkan fisik lingkungan. Menurut Borror et al., (1992), Ceratopogonidae merupakan larva akuatik yang hidup di dalam pasir dan memakan tumbuh - tumbuhan yang membusuk.

\section{Kesimpulan dan Saran}

Kesimpulan

a. Dari analisis data menggunakan CANOCO (Canonical Community Ordination) didapatkan ordinasi Sungai Biru dari 15 stasiun didapat ordinasi A yang menempati daerah ordinasi sebelah 
kiri sebanyak 7 stasiun yang mencerminkan kondisi perairan yang sehat dan ordinasi B yang berada pada ordinasi sebelah kanan sebanyak 8 stasiun yang mencerminkan kondisi daerah perairan yang mulai mengalami degradasi bahan organik yang ditinjau dari tinggi detritus, plume dan lokal NPS; b. Makrozoobenthos yang menyusun ordinasi A yang menandakan perairan sehat yaitu famili Ephrydidae, Argyronela, Limnephilidae, Psephenidae, Hydrophilidae, Bleparoceritidae, Elmidae larva, Glosossomatidae, Leptoceridae, Perlidae, Tipulidae, Chironominae, Baetidae, Philopotamidae, Caenidae, Heptagenidae, Gyrinidae, Hygrobiidae, Dysticidae Platambus, Pholicentropodidae, Dysticidae, Dixidae Muscidae, Haplotaxidae, Tabanidae, Gammaridae, Megaloptera dan Noctuidae. Ordinasi A tersebut berada pada stasiun 1, 2, 4, 7, 9, 10, dan 12.; c. Daerah makrozoobenthos yang menyusun ordinasi B yang menandakan perairan mulai terdegradasi, dimana keberadaan naungan dan CPOM yang mulai berkurang diantaranya famili Hydropsychidae, Simuliidae, Planorbidae, Libellulidae, Porifera, Ceratopogonidae, Tricladida,Lepidostomatidae,Lumbriculidae, Ta nypodinae, Orthocladinae, Coleoptera sp., Psychomidae, Gerridae, Hemiptera sp. dan Hydrobiidae, dimana spesies tersebut terdapat pada stasiun $3,5,6,8,9,13,14$, dan 15. Stasiun 12 dapat dikatakan terdegradasi apabila dilihat dari fisik lingkungannya, dan stasiun 3, 5, dan 6 dapat dikatakan berkualitas air baik walaupun fisik lingkungannya mulai terdegradasi.

\section{Saran}

a. Penelitian lebih lanjut mengenai ordinasi wilayah DAS berdasarkan keberadaan makrozoobenthos yang didukung dengan pengamatan kualitas air.; b. Untuk mendeteksi adanya degradasi kesehatan perairan sungai, alat monitoring yang tepat adalah menggunakan makrozoobenthos; c. Perencanaan pengelolaan DAS terpadu, khususnya Sungai Biru perlu dilakukan, yaitu dengan melibatkan semua "stakeholder" terkait guna menjaga kawasan perairan yang mencerminkan kondisi perairan yang sehat atau mengupayakan kegiatan rehabilitasi lahan guna mengembalikan kondisi perairan yang mulai terdegradasi. Contoh stakeholder tersebut yaitu melibatkan LSM dari masyarakat disekitar wilayah Sungai Biru yaitu seperti "fokalmesra", Bapeda Kota Batu, serta semua masyarakat di sekitar Sungai Biru.

\section{Daftar Pustaka}

Allan, J.D. 1995. Stream Ecology, Structure and Function of Running Waters. School of Natural Resourches and Environment, University of Michigan. USA

APHA. 1985. Standard Methods for Examination of Water. 16 th Edition. American Public Health Association 1015 Fifteenth Street NW Washington DC

Barus, T.A. 2002. Pengantar Limnologi. Jurusan Biologi Fakultas MIPA. Universitas Sumatra Utara. Medan

Borror, D.J., C. A. Triplehorn, dan N.F. Johnson. 1992. Pengenalan Pelajaran Serangga. Edisi Keenam. Diterjemahkan oleh S. Partosoedjono, IPB. Gadjahmada University Press. Yogyakarta.

Effendie, H. 2003. Telaah Kualitas Air. Bagi Pengolahan Sumber Daya dan Lingkungan Perairan. Kanisius.Yogyakarta

ESP (Environmental Service Program). 2005. Data Inventarisasi Mata Air Wilayah Dinas Sumberdaya Air Dan Energi Kota Batu. ESP - USAID. Malang

Hynes, H.B.N. 1972. The Ecology of Running Waters. $2^{\text {nd }}$ Edition. Liverpol University Press. Liverpol 
Marzuki. 1983. Metodologi Riset. Cetakan Ketiga. Bagian Penerbitan Fakultas Ekonomi Universitas Islam Indonesia. Yogyakarta

Macdonald, G.L. 2000. Freshwater Benthic Ecology and Aquatic Entomology Homepage. Akses tanggal 21 Juli 2008. Alamat situs http://www.lakes.chebucto.org/ ZOOBENTH/BENTHOS/benthos.htm 1

Merrit, R.W. dan K.W. Cummins. 1979. An Introduction to The Aquatic Insects of North America. Kendall/Hunt Publishing Company. Iowa. United States of America.

Mulyanto. 1992. Diktat Kuliah Manajemen Perairan. Fakultas Perikanan Universitas Brawijaya. Malang

Nazir, M. 2003. Metode Penelitian. Ghalia Indonesia. Jakarta

Odum, E. 1993. Dasar - Dasar Ekologi. Edisi Pertama. Alih Bahasa T Samingan.Penerbit Gajah Mada University Press. Yogyakarta

Sudaryanti, S. 1995. Classificasion and Ordination Macroinvertebrate Communities In The Brantas River, East Java Related to Environmental Variables. Department of Water Quality Management and Aquatic Ecology, Wageningen Agricultural University. The Netherlands

Sudaryanti, S. 1997. Prosiding Pelatihan: Strategi Pemantauan Kualitas Air Sungai Secara Biologi. Buku II, Materi Pelatihan. Program Studi Manajemen Sumberdaya Perairan Fakultas Perikanan Universitas Brawijaya. Malang
Sudaryanti, S. 1998. Studi Pendahuluan Mengenai Penggunaan Teknik Analisis Multivariate Untuk Menduga Kondisi Ekologis Sungai Brantas. Symposium on Environmental Chemistry and Toxicology. Yogyakarta

Sudaryanti, S. 2000. Status Pengetahuan tentang Potensi Serangga Akuatik dan Pengembangannya sebagai Indikator Cemaran Air. Prosiding Simposium Keanekaragaman Hayati Artropoda pada Sistem Produksi Pertanian. Diterbitkan oleh Perhimpunan Entomologi Indonesia dan Yayasan Keanekaragaman Hayati Indonesia. Bogor

Sudaryanti, S. 2003a. Pemanfaatan Serangga Sebagai Indikator Pencemaran Perairan. Disampaikan dalam Seminar Perhimpunan Biologi dan Perhimpunan Entomologi Malang. Diselenggarakan oleh BALITTAS pada tanggal 10 Juni 2003. Malang

Sudaryanti, S. 2003b. Refleksi Pemberdayaan Penelitian Bioassessment untuk Penilaian Kualitas Air Sungai. Disampaikan pada Seminar Biologi Nasional ITS, 14 Oktober 2003. Fakultas Perikanan Universitas Brawijaya. Malang

Sudaryanti, S. 2004b. Petunjuk Teknik Bioassesment. Pengambilan Contoh Makroinvertebrata dengn Jala Tangan. Fakultas Perikanan. Universitas Brawijaya. Malang

Suwignyo, S., B. Widigdo, Y. Wardianto, dan M. Krisanti. 2005. Avertebrata air, Jilid 2. Penebar Swadaya. Depok

Welch, E. B. 1980. Ecological Effect of Waste Apllied Limnology and Pollutant Effect. Cambrige University Press. Washington USA 